\title{
Mental health, compliance with measures and health prospects during the COVID-19 epidemic: the role of health literacy
}

\author{
Lize Hermans $^{1 *}$, Stephan Van den Broucke ${ }^{2}$, Lydia Gisle ${ }^{1}$, Stefaan Demarest ${ }^{1}$ and Rana Charafeddine ${ }^{1}$
}

\begin{abstract}
Background: The importance of health literacy in dealing with the COVID-19 epidemic has been emphasized but scarcely addressed empirically. In this study, the association of health literacy with mental health, compliance with COVID-19 preventive measures and health prospects was assessed in a Belgian context.

Methods: Data were extracted from the third of a series of cross-sectional online COVID-related surveys ( $n=32$, 794). Data collection took place for 1 week starting the 28th of May 2020. People residing in Belgium and aged 18 years or older could participate. Data were collected on sociodemographic background, health literacy, multimorbidity, mental health (depression, anxiety, sleeping disorder, vitality), knowledge about COVID-19, compliance with COVID-19 measures (hygiene, physical distance, covering mouth and nose on public transport and in places where physical distance cannot be respected), and health prospects (risk for health when returning to normal life and possibility of infection). Prevalence Ratio (PR) of poor mental health, non-compliance with the measures and health prospects in relation to health literacy were calculated using Poisson regressions.

Results: People showing sufficient health literacy were less likely to suffer from anxiety disorders ( $P R=0.47,95 \%$ $\mathrm{Cl}=[0.42-0.53])$, depression $(\mathrm{PR}=0.46,95 \% \mathrm{Cl}=[0.40-0.52])$ and sleeping disorders $(\mathrm{PR}=0.85,95 \% \mathrm{Cl}=[0.82-0.87])$, and more likely to have optimal vitality $(P R=2.41,95 \% \mathrm{Cl}=[2.05-2.84]$ ) than people with low health literacy. They were less at risk of not complying with the COVID-19 measures (PR between 0.60 and 0.83) except one (covering mouth and nose in places where physical distance cannot be respected). Finally, they were less likely to perceive returning to normal life as threatening $(\mathrm{PR}=0.70,95 \% \mathrm{Cl}=[0.65-0.77])$ and to consider themselves at risk of an infection with COVID-19 (PR $=0.75,95 \% \mathrm{Cl}=[0.67-0.84])$. The associations remained significant after controlling for COVID-19 knowledge and multimorbidity.
\end{abstract}

Conclusions: These results suggest that health literacy is a crucial factor in managing the COVID-19 epidemic and offer a perspective for future studies that target health literacy in the context of virus outbreaks.

Keywords: Health literacy, COVID-19, Mental health, Preventive measures

\footnotetext{
* Correspondence: lize.hermans@sciensano.be

'Department of Epidemiology and Public Health, Sciensano, Brussels, Belgium

Full list of author information is available at the end of the article
}

(c) The Author(s). 2021 Open Access This article is licensed under a Creative Commons Attribution 4.0 International License, which permits use, sharing, adaptation, distribution and reproduction in any medium or format, as long as you give appropriate credit to the original author(s) and the source, provide a link to the Creative Commons licence, and indicate if changes were made. The images or other third party material in this article are included in the article's Creative Commons licence, unless indicated otherwise in a credit line to the material. If material is not included in the article's Creative Commons licence and your intended use is not permitted by statutory regulation or exceeds the permitted use, you will need to obtain permission directly from the copyright holder. To view a copy of this licence, visit http://creativecommons.org/licenses/by/4.0/ The Creative Commons Public Domain Dedication waiver (http://creativecommons.org/publicdomain/zero/1.0/) applies to the data made available in this article, unless otherwise stated in a credit line to the data. 


\section{Background}

On March 12, 2020 the World Health Organization declared the coronavirus disease 2019 (COVID-19) outbreak a pandemic. Since then, governments worldwide have been taking strong action in the fight against the spread of the virus by implementing unprecedented measures. Citizens are asked to frequently wash their hands, keep sufficient distance from others, wear face masks that cover their mouth and nose in designated places, and limit their social contacts. To encourage people to comply with these preventive measures, authorities have used different approaches, ranging from giving simple recommendations on how to protect oneself against the virus, issuing warnings, and calling upon peoples' sense of responsibility, to imposing legal restrictions and severely penalizing violations. These efforts have only been partially successful, as a significant part of the population does not strictly comply with the recommendations [1]. While to some extent this may be due to forgetfulness, unwillingness to follow rules imposed by authorities, or practical conditions that make strict compliance difficult, non-compliance with preventive measures against COVID-19 may also result from flaws in the communication process and information delivered to the public. Indeed, for instructions to be followed, it is important that people have the ability to easily access them, understand them, accept them, and apply them to their own situation. In other words, they have to be sufficiently health literate in this case.

While its role is not always recognized, health literacy may well be a crucial factor in the control of the epidemic $[2,3]$. In ordinary times, more than one in three people struggle to access, understand, appraise and use information that is necessary to improve or maintain their health $[4,5]$. People who are less educated, who are older, or who have a lower social status are more at risk of showing low health literacy [4]. Yet whereas the positive effect of health literacy on the prevention and self-management of non-communicable diseases has been well established [6], the literature focusing on health literacy in relation to infectious diseases is limited and fragmented [7].

Given the recency of the coronavirus outbreak, the literature on health literacy and COVID-19 is only beginning to emerge [8]. A few studies have been published since the outbreak looking at health literacy skills that are specific to COVID-19 [9] or investigating online searches for information about the pandemic [10]. Based on the literature and theory regarding health literacy, one would expect that people with higher levels of health literacy are more likely to adopt behaviors that may help contain the epidemic, such as handwashing, facial mask wearing and physical distancing. However, the role of health literacy in the compliance with preventive measures against COVID-19 has thus far only marginally been addressed $[1,11]$. Being health literate might also reduce the impact of the stress caused by the COVID-19 pandemic on mental health. Healthcare workers who are at the frontline are at high risk of burnout, anxiety, depression and post-traumatic stress disorder $[12,13]$. Furthermore, the spread of the coronavirus and the confinement measures that have been taken to prevent this spread may impact the mental health of the general population [12, 14-16]. Indeed, researchers in many countries found that the mental health of the population has deteriorated since the outbreak of the virus [17-22]. So far, the relationship between health literacy and mental health during the COVID-19 pandemic has solely been explored in three studies, the results of which suggest a buffering effect of health literacy [23-25].

The potential adverse effect of low health literacy on the compliance with preventive measures and on mental health may be influenced by the huge media and social media coverage about the pandemic, which some authors refer to as the COVID-19 infodemic [26]. As this abundance of often contradictory information is not only confusing, but can also contain misleading or even downright incorrect information, it is even more important for people to carefully consider the information sources and have the necessary skills to distinguish between reliable and unreliable information [27-29].

Finally, health literacy may also affect how people perceive their future health. Research has shown that people with low health literacy are less accurate at risk perception [30, 31]. In the context of COVID-19, it has been reported that low health literacy is associated with lower fear of the virus [32], but it is not known whether it also has a positive effect on how people perceive their personal risk of contracting the virus or the risk for their health when returning to normal life.

So, while it can be assumed that health literacy is of vital importance to deal with the COVID-19 pandemic in several ways, the evidence to support that view is scarce. This study aimed to address this deficit by assessing the association of health literacy with non-compliance of the preventive measures against COVID-19, mental health, and health prospects. The hypothesis was that people with higher levels of health literacy would better comply with the preventive measures, would exhibit better mental health, and would have more positive health prospects than people with low health literacy.

\section{Methods}

\section{Participants}

To study the impact of the COVID-19 pandemic on the perceived health status and preventive behavior of the population in Belgium, Sciensano, the national institute 
of health, organized a series of cross-sectional online surveys. The first COVID-19 health survey was launched 3 weeks after the start of a nation-wide confinement imposed by the government following the outbreak of the pandemic (2nd of April), the second survey took place 2 weeks later (16th of April), and the third one on the 28th of May 2020, when the confinement was partially eased. Every survey remained online for 1 week. The launch of the surveys was announced in the press as well as on the website and social media of Sciensano and of other organizations (health insurance organizations, community centers...). Participation was based on snowball sampling [33], in the sense that respondents were asked to share the link to the survey with their family, friends and acquaintances residing in Belgium and aged 18 years and older. People younger than 18 or not living in Belgium could not participate and thus were excluded from the study. Participants who had agreed in a given survey to take part in the next one received an invitation through the e-mail address they provided. All methods were carried out in accordance with relevant guidelines and regulations. The survey was approved by the ethical committee of the Ghent University Hospital (BC-07544) and informed consent was obtained from all participants.

Since health literacy was only assessed in the third survey, data were extracted from this survey. A total of 37, 409 people visited the website of the survey but only data from people who provided information on their age, gender, zip code and educational level were retained. The final sample consisted of 32,794 participants.

\section{Measures}

An overview of the measures that were used for the study, including all the questions and answer categories, can be found in the supplementary materials.

\section{Health literacy}

Health literacy was assessed using the revised European Health Literacy Survey Questionnaire $\left(\mathrm{HLS}_{19}\right.$-Q12), developed by the international M-POHL Consortium as a revised version of the European Health Literacy Survey Questionnaire. The latter was developed for the European Health Literacy study (HLS-EU) and has been translated and used in a large number of countries [34]. The derived HLS ${ }_{19}-\mathrm{Q} 12$ has been validated in Europe [35] and consists of 12 items that reflect the dimensions of health literacy proposed in the model of Sørensen et al. [36], assessing how easy or difficult it is for people to find, understand, appraise health information and act accordingly. People with low health literacy were identified using the method described by Sørensen et al. [4] and Pelikan et al. [34]. In accordance with the European Health Literacy Survey, the score for health literacy was standardized into a scale from 0 to $50\left(\mathrm{HL}=(\text { mean }-1)^{*}(50 / 3)\right)$, and on this basis two categories of health literacy were defined: low health literacy (score of 0-33) and sufficient health literacy (score of $>33-50$ ).

\section{Outcome measures}

Three outcomes were examined in this study: mental health, non-compliance with preventive measures and health prospects.

Mental health The presence of anxiety and depression was assessed using the Generalized Anxiety Disorder Scale (GAD-7) and the Patient Health Questionnaire (PHQ-9), respectively. The presence of a sleeping disorder was assessed by the Symptom Checklist - 90 Revised (SCL-90-R) [37]. Optimal vitality was assessed using the four items of the RAND SF-36-V2 [38].

Non-compliance with the preventive measures The participants' compliance with the preventive measures to reduce the spread of the virus was assessed using a simple question with "low respect", "partial respect" and "strict respect" as answer categories for each of the following recommended behaviors: hand hygiene (washing hands regularly, coughing in elbow, ...), maintaining a distance of at least $1.5 \mathrm{~m}$ from people (except for the people you live with), covering mouth and nose with a face mask, scarf or bandana on public transport, and covering mouth and nose in places where a distance of $1.5 \mathrm{~m}$ cannot be guaranteed.

Health prospects Health prospects were assessed by two questions to be scored on Likert-type scales: (1) the perceived health risk of returning to normal life, scored on a 4-point Likert-type scale ranging from very low to very high risk, and (2) the likelihood of a future COVID19 infection, scored on a 5-point Likert-type scale ranging from very unlikely to very likely.

\section{Covariates}

Multimorbidity was measured with the question "In the 12 months prior to 13 March, did you have any of the following diseases or conditions?" (Yes/No) (followed by a list of 16 frequent chronic diseases). Knowledge about COVID-19 was measured by six direct questions asking whether the respondent considered him/herself sufficiently informed about the following issues: preventive measures against a coronavirus (COVID-19) infection, symptoms of a coronavirus (COVID-19) infection, the treatment of a coronavirus (COVID-19) infection, the spread of the coronavirus, the easing of the containment and quarantine measures, and the availability of shops and services during corona. All questions were scored 
on a 2-point scale (sufficiently informed - not sufficiently informed) and summed.

\section{Statistical analyses}

Following an inspection of descriptive statistics for all the variables, Poisson regressions modeling were used to study the association of each of the three outcomes (mental health, the non-compliance with preventive measures and the health prospects) with health literacy during the COVID-19 pandemic. Two models were estimated for each outcome variable. The first model controlled for sex (male/female), age groups $(18-24,25-34,35-44,45-54,55-64,65+)$, and education (secondary education or lower, higher than secondary education). Educational level is an important confounder due to its association with health literacy and with the studied outcomes. For the second model, multimorbidity ( 0 disease, 1-2 diseases, 2 or more diseases) and knowledge about COVID-19 (low knowledge versus sufficient knowledge) were added. Multimorbidity was included in the model because people's reaction to the COVID-19 epidemic may vary if a person had a chronic disease.
Knowledge about COVID-19 was included to control for knowledge in relation to literacy. Missing values for the explanatory variables were treated as a separate category.

Post-stratification weights were used in all the analyses to align the sample to the Belgian population in terms of age, sex, province and educational level. Confidence intervals were calculated at the $95 \%$ level. The analyses were performed in STATA 16 using appropriate svy commands.

\section{Results}

Table 1 presents the distribution of the participants' characteristics in terms of sociodemographic and explanatory variables. The table includes the weighted percentage of the missing values for each explanatory variable. The results showed that $23 \%$ of the general population had low levels of health literacy while 56\% had sufficient levels. If the missing values for health literacy were excluded (21\%), the percentages would be $29 \%$ and $71 \%$, respectively.

Table 2 presents the prevalence of the outcome measures in the general population and by health literacy

Table 1 Distribution of the study population $(N=32,794)$ by sociodemographic covariates and explanatory variables

\begin{tabular}{|c|c|c|c|c|}
\hline & \multirow{2}{*}{$\begin{array}{l}\text { All } \\
\text { (weighted \%) }\end{array}$} & \multicolumn{3}{|c|}{ Health literacy (weighted \%) } \\
\hline & & Low & Sufficient & Missing \\
\hline \multicolumn{5}{|l|}{ Gender } \\
\hline Male & 49.05 & 23.91 & 53.68 & 22.42 \\
\hline Female & 50.95 & 21.37 & 58.73 & 19.90 \\
\hline \multicolumn{5}{|l|}{ Age group (years) } \\
\hline $18-24$ & 13.75 & 28.36 & 38.67 & 32.97 \\
\hline $25-34$ & 15.70 & 26.81 & 48.13 & 25.06 \\
\hline $35-44$ & 15.73 & 22.19 & 55.73 & 22.08 \\
\hline $45-54$ & 16.64 & 22.15 & 59.30 & 18.54 \\
\hline $55-64$ & 16.02 & 20.84 & 62.86 & 16.29 \\
\hline $65+$ & 22.16 & 18.01 & 66.19 & 15.79 \\
\hline \multicolumn{5}{|l|}{ Education } \\
\hline Secondary education or lower & 67.15 & 23.91 & 52.93 & 23.16 \\
\hline Higher education & 32.85 & 19.97 & 63.04 & 16.99 \\
\hline \multicolumn{5}{|l|}{ Multimorbidity } \\
\hline 0 disease & 51.96 & 21.97 & 57.55 & 20.48 \\
\hline $1-2$ diseases & 25.18 & 23.69 & 61.02 & 15.29 \\
\hline 2 or more diseases & 12.71 & 26.18 & 59.38 & 14.44 \\
\hline Missing & 10.15 & 18.80 & 33.83 & 47.38 \\
\hline \multicolumn{5}{|l|}{ Knowledge about COVID-19 } \\
\hline Limited & 29.63 & 42.14 & 43.08 & 14.78 \\
\hline Sufficient & 57.54 & 16.32 & 73.58 & 10.09 \\
\hline Missing & 12.82 & 5.73 & 8.90 & 85.37 \\
\hline All & 100 & 22.62 & 56.25 & 21.14 \\
\hline
\end{tabular}


Table 2 Prevalence of mental health, compliance with measures and health prospects in the general population

\begin{tabular}{|c|c|c|c|c|}
\hline & & Health & & \\
\hline & (weighted \%) & Low & Sufficient & Missing \\
\hline Mental he & & & & \\
\hline Anxiety & & & & \\
\hline Yes & 16.06 & 27.07 & 11.32 & 17.23 \\
\hline No & 83.94 & 72.93 & 88.68 & 82.77 \\
\hline Depress & & & & \\
\hline Yes & 15.16 & 26.43 & 10.53 & 15.58 \\
\hline No & 84.84 & 73.57 & 89.47 & 84.42 \\
\hline Sleeping & & & & \\
\hline Yes & 72.01 & 81.59 & 68.57 & 70.63 \\
\hline No & 27.99 & 18.41 & 31.43 & 29.37 \\
\hline Optimal & & & & \\
\hline Yes & 15.75 & 7.22 & 19.70 & 14.06 \\
\hline No & 84.25 & 92.78 & 80.30 & 85.94 \\
\hline Complian & & & & \\
\hline Hygiene & & & & \\
\hline Yes & 81.65 & 76.76 & 84.65 & 76.13 \\
\hline No & 18.35 & 23.24 & 13.35 & 23.87 \\
\hline Keeping & $=29,983)$ & & & \\
\hline Yes & 74.47 & 68.84 & 77.89 & 68.27 \\
\hline No & 25.53 & 31.16 & 22.11 & 31.73 \\
\hline Coverin & public transport & & & \\
\hline Yes & 94.98 & 93.50 & 96.15 & 91.47 \\
\hline No & 5.02 & 6.50 & 3.85 & 8.53 \\
\hline $\begin{array}{l}\text { Coverin } \\
\text { cannot }\end{array}$ & $\begin{array}{l}\text { places where phy } \\
01 \text { ) }\end{array}$ & & & \\
\hline Yes & 72.77 & 70.06 & 75.07 & 65.87 \\
\hline No & 27.23 & 29.94 & 24.93 & 34.13 \\
\hline Health pr & & & & \\
\hline High ris & rning to normal I & & & \\
\hline Yes & 24.68 & 30.06 & 22.76 & 23.45 \\
\hline No & 75.32 & 69.94 & 77.24 & 76.55 \\
\hline Likely to & /ID-19 $(n=29,358$ & & & \\
\hline Yes & 18.48 & 23.90 & 16.73 & 16.30 \\
\hline No & 81.52 & 76.10 & 83.27 & 83.70 \\
\hline
\end{tabular}

status, and includes the number of participants for each outcome measure. At this stage of the epidemic, almost $16 \%$ of the participants were found to suffer an anxiety disorder, and 15\% a depression, while $72 \%$ experienced a sleeping disorder and only $16 \%$ met the optimal vitality threshold. These percentages were higher for respondents with a low level of health literacy compared to those with sufficient health literacy.
The prevalence of non-compliance of preventive measures varied depending on the measure considered. Only $5 \%$ of the respondents indicated that they did not strictly comply with measure of covering their mouth and nose on public transport, whereas $27 \%$ indicated they did not strictly comply with the measure of covering mouth and nose in places where physical distance could not be guaranteed. Maintaining a physical distance of at least $1.5 \mathrm{~m}$ was not strictly followed by $26 \%$ of the 
respondents, and hygiene measures (handwashing) by $18 \%$. Again, the percentages of non-complying with preventive measures were higher for respondents with low health literacy.

With respect to health prospects, approximately one out of four respondents thought that returning to normal life entailed a high risk for their own health, and one out of five thought they were likely to become infected with the coronavirus in the coming months. These percentages were again higher for respondents with low health literacy.

Table 3 presents the prevalence ratio (PR) of the outcomes in relation to health literacy. Health literacy was significantly associated with mental health during the COVID-19 pandemic. Specifically, people with sufficient health literacy were less likely to suffer from anxiety disorders, depression and sleeping disorders than those with low health literacy, and were more than twice as likely to have an optimal level of vitality. The association remained significant after controlling for knowledge about COVID19 and multimorbidity. Health literacy was also significantly associated with non-compliance of the COVID-19 measures, with the risk of not adhering being lower for participants with sufficient health literacy than for those with low health literacy for all but one measure (covering mouth and nose in places where the physical distance cannot be respected). The associations remained significant after controlling for knowledge about COVID-19 and multimorbidity. We also found significant associations between health literacy and health prospects, in the sense that respondents with sufficient health literacy were less likely to perceive returning to normal life as risky than those with low health literacy. They were also less likely to consider themselves at risk of an infection with COVID-
19 in the future. Again, the results remained significant after controlling for knowledge about COVID-19 and multimorbidity.

\section{Discussion}

Health literacy is considered a critical concept for public health, the importance of which is attested by the large body of scientific literature that relates health literacy to medication and health service use, adherence to disease self-management, use of preventive services, participation in screening and vaccination programs, and engagement in health promoting behaviors [39]. Yet despite this agreed-upon importance, the role of health literacy in adopting preventive measures against COVID-19 has scarcely been examined empirically. This survey study, involving a large sample of the Belgian population, investigated whether health literacy is related to the likelihood of people to adopt behaviors that help to contain the epidemic, notably hand hygiene, physical distancing, and wearing a face mask or other protection covering nose and mouth on public transport and in places where a physical distance of at least $1.5 \mathrm{~m}$ cannot be guaranteed. The results indicate that people with low levels of health literacy are less likely to comply with the preventive behavioral measures. Moreover, they also report more mental health problems, and have a more negative perspective of future health than people with sufficient health literacy.

The results of this study showed that $29 \%$ of the Belgian population have low levels of health literacy. This is comparable to previous Belgian population surveys: in the Health Interview Survey 2018 [40] 33\% of the respondents were found to have low levels of health literacy. People with sufficient health literacy were less

Table 3 Mental health, non-compliance with the measures and health prospects during the COVID-19 pandemic in people with low (baseline) versus sufficient health literacy

\begin{tabular}{llll}
\hline & & \multicolumn{1}{l}{$\begin{array}{l}\text { Health literacy PR (95\% Cl) } \\
\text { Model 1 }\end{array}$} & $\begin{array}{l}\text { Health literacy PR (95\% Cl) } \\
\text { Model } 2\end{array}$ \\
\hline Mental health & Anxiety disorder & $0.47(0.42-0.53)^{* * *}$ & $0.56(0.49-0.63)^{* * *}$ \\
& Depression & $0.46(0.40-0.52)^{* * *}$ & $0.54(0.47-0.62)^{* * *}$ \\
& Sleeping disorder & $0.85(0.82-0.87)^{* * *}$ & $0.88(0.85-0.91)^{* * *}$ \\
& Optimal vitality & $2.41(2.05-2.84)^{* * *}$ & $2.13(1.81-2.50)^{* * *}$ \\
Non-compliance & Hygiene measures & $0.74(0.66-0.83)^{* * *}$ & $0.76(0.68-0.86)^{* * *}$ \\
& Phith... & $0.83(0.76-0.91)^{* * *}$ & $0.86(0.78-0.94)^{* *}$ \\
& Covering mouth and nose on public transport & $0.60(0.47-0.77)^{* * *}$ & $0.64(0.50-0.83)^{* *}$ \\
& Covering mouth and nose in places where physical distance & $0.92(0.84-1.00)$ & $0.92(0.84-1.01)$ \\
cannot be respected & & $0.79(0.73-0.87)^{* * *}$ \\
& High risk for health when returning to normal life & $0.70(0.65-0.77)^{* * *}$ & $0.81(0.72-0.91)^{* * *}$ \\
\hline
\end{tabular}

Poisson regressions. Model 1 includes age group, gender, education and health literacy. Model 2 includes age group, gender, education, health literacy, knowledge COVID-19 and multimorbidity. $P R$ Prevalence ratio, $C l$ Confidence interval

${ }^{* *} p<.01,{ }^{* * *} p<.001$ 
likely not to comply with the preventive measures. Furthermore, those with sufficient health literacy were less likely to suffer from a depression, anxiety or sleeping disorder. This is in agreement with Nguyen et al. [25] who reported lower odds of depression with higher levels of health literacy. Furthermore, Duplaga et al. [23] showed that higher health literacy was associated with lower levels of future anxiety during the COVID-19 pandemic. As such, these findings confirm the importance of health literacy in people's reaction to the pandemic, and suggest that health literacy should be taken in account in order to address (the consequences of) the pandemic effectively.

Taking health literacy in account implies that the communication about COVID-19 and about the preventive measures needs to be adapted to the literacy needs of the people. According to Okan, Sørensen and Messer [41] this may involve: presenting information in a comprehensible manner and adapting the type and amount of communication to your audience (e.g. using animations for people with low health literacy); clarifying that evidence on the virus is advancing and new information might emerge that may lead to recommendations being modified; communicating new information on the virus and if needed correcting earlier messages. It also involves countering false or misleading information about COVID by encouraging people to cross-check its accuracy and credibility, to check the information sources and verify the information by consulting a second source, to consult trusted health professionals about information that is suspect, and to not share information that has not been fact-checked [41]. Given the unprecedented coverage of the pandemic in traditional mass media and on social media, which often adds to the confusion [26], it is an important task for both conventional and social media to ensure that the information that is provided on COVID-19 and on the precautionary measures is correct [42], comprehensive, transparent, consistent, supportive and easy to understand [42-44].

In addition to calling for an adaptation and improvement of the communication about the pandemic and the response to it, our findings also emphasize the continuing need to improve the health literacy of the population [45], so as to enable people to make sound health decisions in the context of the pandemic and beyond. Such an improvement is not only a task of the health sector, but requires action at different levels, including governmental agencies and the media [46]. Such actions could include, amongst others, the development of guidelines to ensure better health communication comprehensible to people with low health literacy, the inclusion of health literacy in the training curricula of health workers, implementing health literacy programs in school settings [47], the creation and strengthening of health literacy- friendly settings, and the development of policies for health literacy at the local, national and international level.

This study is not without its limitations. As the survey was only made available online and a snowball sampling technique was used to recruit participants, the results may not be representative of the entire population, despite the fact that a weighing of the data for age, sex and education was applied to improve representativeness. Also, a relatively large number of respondents (approximately 20\%) did not complete or only partially completed the questions on health literacy. On the other hand, the percentage of respondents with a sufficient level of health literacy is comparable to that of previous population surveys in Belgium [48]. Lastly, as the study design was cross-sectional, the causality of the relationship between health literacy and the outcome variables cannot be inferred.

Despite these limitations, however, the results of this study are sufficiently robust to assert the importance of health literacy as a determinant of people's reactions to COVID-19. While offering evidence that health literacy should be taken in account to more efficiently curb the pandemic, they also offer a perspective for future studies that target health literacy in the context of virus outbreaks.

\section{Abbreviations \\ Cl: Confidence interval; COVID-19: Coronavirus disease 2019; GAD- 7: Generalized Anxiety Disorder Scale; $\mathrm{HLS}_{19}-\mathrm{Q} 12$ : European Health Literacy Survey Questionnaire; PHQ-9: Patient Health Questionnaire; PR: Prevalence Ratio; SF-36: Short Form 36}

\section{Supplementary Information}

The online version contains supplementary material available at https://doi. org/10.1186/s12889-021-11437-w.

Additional file 1: Supplementary 1. Overview of the creation of the indicators based on the questions and answer categories in the third COVID-19 health survey.

\section{Acknowledgements}

We would like to thank the participants in the surveys and colleagues in the Health Surveys Unit.

\section{Authors' contributions}

LH, LG, SD and RC participated in the design of the study and collected the data. $\mathrm{LH}$ and RC performed the analyses. $\mathrm{LH}, \mathrm{RC}$ and SVdB drafted the first manuscript. All authors contributed to revising the manuscript. All authors read and approved the final manuscript.

\section{Funding}

The COVID-19 health survey was funded by internal Sciensano funds.

Availability of data and materials

The dataset used and/or analysed during the current study is available from the corresponding author following a request to the Health Interview Survey team at Sciensano and a signature of a Data Transfer Agreement. 


\section{Declarations}

\section{Ethics approval and consent to participate}

All methods were carried out in accordance with relevant guidelines and regulations. The survey was approved by the ethical committee of the Ghent University Hospital (BC-07544) and informed consent was obtained from all participants.

\section{Consent for publication}

Not applicable.

\section{Competing interests}

The authors declare that they have no competing interests.

\section{Author details}

'Department of Epidemiology and Public Health, Sciensano, Brussels, Belgium. ${ }^{2}$ Université Catholique de Louvain, Louvain-la-Neuve, Belgium.

Received: 18 January 2021 Accepted: 15 June 2021

Published online: 10 July 2021

\section{References}

1. Block R, Berg A, Lennon RP, Miller EL, Nunez-Smith M. African American adherence to COVID-19 public health recommendations. Heal Lit Res Pract. 2020:4(3):e166-70. https://doi.org/10.3928/24748307-20200707-01.

2. Paakkari L, Okan O. COVID-19: health literacy is an underestimated problem. Lancet. 2020:19-21. https://doi.org/10.1007/s00134-020-05991-x.Bizzarro.

3. Van den Broucke S. Why health promotion matters to the COVID-19 pandemic, and vice versa. Health Promot Int. 2020;35(2):181-6. https://doi. org/10.1093/heapro/daaa042.

4. Sørensen K, Pelikan JM, Röthlin F, Ganahl K, Slonska Z, Doyle G, et al. Health literacy in Europe: comparative results of the European health literacy survey (HLS-EU). Eur J Pub Health. 2015;25(6):1053-8. https://doi.org/10.1 093/eurpub/ckv043.

5. Duong TV, Aringazina A, Kayupova G, Nurjanah PTV, Pham KM, et al. Development and validation of a new short-form health literacy instrument (HLS-SF12) for the general public in six Asian countries. HLRP Heal Lit Res Pract. 2019;3(2):e91-102. https://doi.org/10.3928/24748307-20190225-01.

6. Vamos S, Rootman I. Health literacy as a lens for understanding noncommunicable diseases and health promotion. In: McQueen DV, editor. Global handbook on noncommunicable diseases and health promotion. New York: Springer New York; 2013. p. 169-87. https://doi.org/10.1007/ 978-1-4614-7594-1_11.

7. McQueen DV, Manoncourt E, Cartier YN, Dinca I, Nurm Ü-K. The transferability of health promotion and education approaches between non-communicable diseases and communicable diseases-an analysis of evidence. AIMS Public Heal. 2014;1(4):182-98. https://doi.org/10.3934/ publichealth.2014.4.182.

8. Matterne U, Egger N, Tempes J, Tischer C, Lander J, Dierks M-L, et al. Health literacy in the general population in the context of epidemic or pandemic coronavirus outbreak situations: rapid scoping review. Patient Educ Couns. 2020;104(2):223-234. https://doi.org/10.1016/j.pec.2020.10.012.

9. Okan O, Bollweg TM, Berens E-M, Hurrelmann K, Bauer U, Schaeffer D. Coronavirus-related health literacy: a cross-sectional study in adults during the COVID-19 Infodemic in Germany. Int J Environ Res Public Health. 2020; 17(15):5503. https://doi.org/10.3390/ijerph17155503.

10. Xu C, Zhang X, Wang Y. Mapping of health literacy and social panic via web search data during the COVID-19 public health emergency: Infodemiological study. J Med Internet Res. 2020;22(7):1-8. https://doi.org/1 $0.2196 / 18831$

11. Lennon RP, Sakya SM, Miller EL, Snyder B, Yaman T, Zgierska AE, et al. Public intent to comply with COVID-19 public health recommendations. HLRP Heal Lit Res Pract. 2020;4(3):e161-5. https://doi.org/10.3928/247483 07-20200708-01

12. Vindegaard N, Benros ME. COVID-19 pandemic and mental health consequences: systematic review of the current evidence. Brain Behav Immun. 2020:89:531-42. https://doi.org/10.1016/j.bbi.2020.05.048.

13. Chirico F, Nucera G, Magnavita N. Protecting the mental health of healthcare workers during the COVID-19 emergency. BJPsych Int. 2021;18(1): 1-2. https://doi.org/10.1192/bji.2020.39.
14. Qiu J, Shen B, Zhao M, Wang Z, Xie B, Xu Y. A nationwide survey of psychological distress among Chinese people in the COVID-19 epidemic: implications and policy recommendations. Gen Psychiatry. 2020;33(2): 100213. https://doi.org/10.1136/gpsych-2020-100213.

15. Wang C, Pan R, Wan X, Tan Y, Xu L, Ho CS, et al. Immediate psychological responses and associated factors during the initial stage of the 2019 Coronavirus disease (COVID-19) epidemic among the general population in China. Int J Environ Res Public Health. 2020:17(5). https://doi.org/10.3390/ ijerph17051729.

16. Brooks SK, Webster RK, Smith LE, Woodland L, Wessely S, Greenberg N, et al. The psychological impact of quarantine and how to reduce it: rapid review of the evidence. Lancet. 2020;395(10227):912-20. https://doi.org/10.1016/ s0140-6736(20)30460-8.

17. Ahmed MZ, Ahmed O, Aibao Z, Hanbin S, Siyu L, Ahmad A. Epidemic of COVID-19 in China and associated psychological problems. Asian J Psychiatr. 2020;51:102092. https://doi.org/10.1016/j.ajp.2020.102092.

18. McGinty EE, Presskreischer R, Han H, Barry CL. Psychological distress and loneliness reported by US adults in 2018 and April 2020. JAMA. 2020;324(1): 93-4. https://doi.org/10.1001/jama.2020.9740.

19. White RG, Van Der Boor C. Impact of the COVID-19 pandemic and initial period of lockdown on the mental health and well-being of adults in the UK. BJPsych Open. 2020;6(5):e90. https://doi.org/10.1192/bjo.2020.79.

20. Pierce $M$, Hope $H$, Ford T, Hatch S, Hotopf M, John A, et al. Mental health before and during the COVID-19 pandemic: a longitudinal probability sample survey of the UK population. Lancet Psychiatry. 2020;7(10):883-92. https://doi.org/10.1016/S2215-0366(20)30308-4.

21. Rossi R, Socci V, Talevi D, Mensi S, Niolu C, Pacitti F, et al. COVID-19 pandemic and lockdown measures impact on mental health among the general population in Italy. Front Psychiatry. 2020;11:790. https://doi.org/1 0.3389/fpsyt.2020.00790.

22. Lorant V, Smith P, Van den Broeck K, Nicaise P. Psychological distress associated with the COVID-19 pandemic and suppression measures during the first wave in Belgium. BMC Psychiatry. 2021;21:112. https://doi.org/10.11 86/s12888-021-03109-1.

23. Duplaga M, Grysztar M. The association between future anxiety, health literacy and the perception of the COVID-19 pandemic: a cross-sectional study. Healthcare. 2021;9(1):43. https://doi.org/10.3390/healthcare9010043.

24. Do BN, Nguyen P-A, Pham KM, Nguyen HC, Nguyen MH, Tran CQ, et al. Determinants of health literacy and its associations with health-related behaviors, depression among the older people with and without suspected COVID-19 symptoms: a multi-institutional study. Front Public Heal. 2020;8. https://doi.org/10.3389/fpubh.2020.581746.

25. Nguyen HC, Nguyen MH, Do BN, Tran CQ, Nguyen TTP, Pham KM, et al. People with suspected COVID-19 symptoms were more likely depressed and had lower health-related quality of life: the potential benefit of health literacy. J Clin Med. 2020;9(4):965. https://doi.org/10.3390/jcm9040965.

26. Zarocostas J. How to fight an infodemic. Lancet (London, England). 2020; 395(10225):676. https://doi.org/10.1016/S0140-6736(20)30461-X.

27. Dubey S, Biswas P, Ghosh R, Chatterjee S. Psychosocial impact of COVID-19. Diabetes Metab Syndr Clin Res Rev. 2020;14(5):779-88. https://doi.org/10.101 6/j.dsx.2020.05.035

28. van der Linden S, Roozenbeek J, Compton J. Inoculating against fake news about COVID-19. Front Psychol. 2020;11. https://doi.org/10.3389/fpsyg.2020. 566790 .

29. Orso D, Federici N, Copetti R, Vetrugno L, Bove T. Infodemic and the spread of fake news in the COVID-19-era. Eur J Emerg Med. 2020;27(5):327-8. https://doi.org/10.1097/MEJ.0000000000000713.

30. Brewer NT, Tzeng JP, Lillie SE, Edwards AS, Peppercorn JM, Rimer BK. Health literacy and cancer risk perception: implications for genomic risk communication. Med Decis Mak. 2009;29(2):157-66. https://doi.org/10.1177/ $0272989 \times 08327111$

31. Rutherford EJ, Kelly J, Lehane EA, Livingstone V, Cotter B, Butt A, et al. Health literacy and the perception of risk in a breast cancer family history clinic. Surg. 2018;16(2):82-8. https://doi.org/10.1016/j.surge.2016.06.003.

32. Nguyen HT, Do BN, Pham KM, Kim GB, Dam HTB, Nguyen TT, et al. Fear of COVID-19 scale-associations of its scores with health literacy and healthrelated behaviors among medical students. Int J Environ Res Public Health. 2020;17(11):4164. https://doi.org/10.3390/ijerph17114164.

33. Naderifar M, Goli H, Ghaljaie F. Snowball sampling: a purposeful method of sampling in qualitative research. Strides Dev Med Educ. 2017;14(3). https:// doi.org/10.5812/sdme.67670. 
34. Pelikan JM, Ganahl K, Van den Broucke S, Sorensen K. Measuring health literacy in Europe: introducing the European health literacy survey questionnaire (HLS-EU-Q). In: Okan O, Bauer U, Levin-Zamir D, Pinheiro P, Sørensen $\mathrm{K}$, editors. International handbook of health literacy: research, practice and policy across the life-span. Bristol: Policy Press; 2019. p. 115-38. http://hdl.handle.net/2078.1/219963\%0D.

35. Finbråten $\mathrm{HS}$, Wilde-Larsson B, Nordström G, Pettersen $\mathrm{KS}$, Trollvik A, Guttersrud $\varnothing$. Establishing the HLS-Q12 short version of the European health literacy survey questionnaire: latent trait analyses applying Rasch modelling and confirmatory factor analysis. BMC Health Serv Res. 2018;18: 506. https://doi.org/10.1186/s12913-018-3275-7.

36. Sørensen K, Van den Broucke S, Fullam J, Doyle G, Pelikan J, Slonska Z, et al. Health literacy and public health: a systematic review and integration of definitions and models. BMC Public Health. 2012;12:80. https://doi.org/10.11 86/1471-2458-12-80.

37. Derogatis LR. Symptom Checklist-90-R: administration, scoring \& procedure manual for the revised version of the SCL-90. National Computer Systems: Minneapolis; 1994.

38. Ware JE, Snow KK, Kosinski M, Gandek B. SF-36 health survey manual and interpretation guide. Bost New Engl Med Cent. 1993.

39. Van den Broucke S. Health literacy: a critical concept for public health. Arch Public Heal. 2014;72:10. https://doi.org/10.1186/2049-3258-72-10.

40. Charafeddine R, Demarest S, Berete F. Gezondheidsenquête 2018: Gezondheidsvaardigheden. België: Brussel.

41. Okan O, Sørensen K, Messer M. COVID-19: a guide to good practice on keeping people well informed. The Conversation. 2020. https://theconversa tion.com/covid-19-a-guide-to-good-practice-on-keeping-people-wellinformed-134046.

42. Luengo-Oroz M, Hoffmann Pham K, Bullock J, Kirkpatrick R, Luccioni A, Rubel $\mathrm{S}$, et al. Artificial intelligence cooperation to support the global response to COVID-19. Nat Mach Intell. 2020;2:295-7. https://doi.org/10.103 8/s42256-020-0184-3.

43. World Health Organization. Infodemic management: a key component of the COVID-19 global response. Wkly Epidemiol Rec. 2020;95:145-8.

44. Hernández-García I, Giménez-Júlvez T. Assessment of health information about COVID-19 prevention on the internet: Infodemiological study. JMIR Public Heal Surveill. 2020;6(2):e18717. https://doi.org/10.2196/18717.

45. Kickbusch I, Pelikan JM, Apfel F, Tsouros AD. Health literacy: the solid facts. World Health Organization Regional Office for Europe; 2013.

46. Ashrafi-rizi H, Kazempour Z. Information typology in coronavirus (COVID-19) Crisis; a Commentary. Arch Acad Emerg Med. 2020;8(1):e19. https://doi.org/1 0.22037/aaem.v8i1.591.

47. Vamos S, Okan O, Sentell T, Rootman I. Making a case for "Education for Health Literacy": an international perspective. Int J Environ Res Public Health. 2020;17(4):1436. https://doi.org/10.3390/ijerph17041436.

48. Vandenbosch J, Van den Broucke S, Vancorenland S, Avalosse H, Verniest R, Callens M. Health literacy and the use of healthcare services in Belgium. J Epidemiol Community Health. 2016;70:1032-8. https:/doi.org/10.1136/ jech-2015-206910.

\section{Publisher's Note}

Springer Nature remains neutral with regard to jurisdictional claims in published maps and institutional affiliations.

\section{Ready to submit your research? Choose BMC and benefit from:}

- fast, convenient online submission

- thorough peer review by experienced researchers in your field

- rapid publication on acceptance

- support for research data, including large and complex data types

- gold Open Access which fosters wider collaboration and increased citations

- maximum visibility for your research: over $100 \mathrm{M}$ website views per year

At $\mathrm{BMC}$, research is always in progress.

Learn more biomedcentral.com/submissions 